\title{
FUNDAMENTAL INEQUALITIES FOR FRACTIONAL HYBRID DIFFERENTIAL EQUATIONS OF DISTRIBUTED ORDER AND APPLICATIONS
}

\author{
Hossein Noroozi, Alireza Ansari And Mohammad Shafi DaHAghin
}

\begin{abstract}
In this article, we establish some fundamental strict and non-strict differential inequalities for the fractional hybrid differential equations of distributed order (DOFHDEs). We derive these inequalities with respect to a nonnegative density function in the Riemann-Liouville derivative of order $0<q<1$. As an application of these inequalities, we prove the existence results for extremal solution of DOFHDEs and state the comparison principle.
\end{abstract}

Mathematics subject classification (2010): 26A33, 34A40, 34K10, 47H10. inequality.

Keywords and phrases: Fractional hybrid differential equations, distributed order, extremal solutions,

\section{REFERENCES}

[1] M. CAPuto, Elasticita e Dissipazione, Zanichelli, Bologna, Italy, 1969.

[2] M. CAPUTO, Mean fractional-order-derivatives differential equations and filters, Annali dell universita di Ferrara. Nuova Serie. Sezione VII. Scienze Mathematiche, 41 (1995) 73-84.

[3] M. CAPUTO, Distributed order differential equations modeling dielectric induction and diffusion, Fractional Calculas and Applied Analysis, 4 (2001) 421-442.

[4] A. V. Bob Yelv AND C. CERCIGNANI, The inverse laplace transform of some analytic functions with an application to the eternal solutions of the Boltzmann equation, Applied Mathematics Letters, 15 (7) (2002) 807-813.

[5] B. DAVIS, Integral Transforms and their applications, 3rd edition, Springer-Verlag, New York, 2001.

[6] B. C. DHAGE, On a fixed point theorem in Banach algebras with applications, Applied Mathematics Letters, 18 (2005) 273-280.

[7] B. C. DHAGE, A nonlinear alternative in Banach algebras with applications to functional differential equations, Nonlinear Functional Analysis and Applications, 8 (2004) 563-575.

[8] B. C. DhAGE, Nonlinear quadratic first order functional integro-differential equation with periodic boundary conditions, Dynamic Systems and Applications, 18 (2009) 303-322.

[9] B. C. Dhage, Theorical approximation methods for hybrid differential equations, Dynamic Systems and Applications, 20, (2011) 455-478.

[10] B. C. Dhage, V. Lakshmikantham, Basic results on hybrid differential equations, Nonlinear Analysis Hybrid, 4 (2010) 414-424.

[11] B. C. DhaGe, V. LAKShmiKantham, Quadratic perturbations of boundary value problems of second order ordinary differential equations, Differential Equations and Applications, 2 (4) (2010) 465486.

[12] B. C. Dhage And B. D. KARANDe, First order integro-differential equations in banach algebras involving caratheodory and discontinuous nonlinearities, Electronic Journal of Qualitative Theory of Differential Equations, 21, (2005) 1-16.

[13] B. C. Dhage, On $\alpha$-condensing mappings in Banach algebras, Mathematics Student, 63 (1994) $146-152$.

[14] B. C. DHAGE, Fixed point theorems in ordered Banach algebras and applications, Panamerican Mathematical Journal, 9 (4) (1999) 93-102. 
[15] B. C. DhaGE, Differential inequalities for implicit perturbations of first order differential equations with applications, Mathematical Inequalities and Applications (2011), 811-817.

[16] G. B. Folland, Real Analysis: Modern Techniques and Their Applications, 2nd Edition, Wiley, 1999.

[17] A. A. Kilbas, H. M. SRivastava, J. J. Trujillo, Theory and Applications of Fractional Differential Equations, North-Holland Mathematics Studies, 204, Elsevier Science Publishers, Amsterdam, Heidelberg and New York, 2006.

[18] V. Lakshmikantham, S. Leela, Differential and Integral Inequalities, Academic Press, New York, 1969.

[19] V. Lakshmikantham, A. S. Vatsala, Theory of fractional differential inequalities and applications, Communications in Applied Analysis, 11 (2007) 395-402.

[20] H. Noroozi, A. ANSARI, M. SH. DAHAGHIN, Existence results for the distributed order fractional hybrid differential equations, Abstract and Applied Analysis, 2012, ArticleID 163648, 16 pages.

[21] I. Podlubny, Fractional Differential Equations, Academic Press, San Diego, 1999.

[22] Y. ZhaO, S. Sun, Z. HAN, Q. LI, Theory of fractional hybrid differential equations, Computer and Mathematics with Applications, 62 (2011) 1312-1324. 